\title{
AS PRÁTICAS DE LETRAMENTO NA SÍNDROME DE DOWN: A IMPORTÂNCIA DOS GÊNEROS TEXTUAIS
}

\author{
Vivian Meira* \\ Cláudia Madalena Feistauer **
}

RESUMO: Este texto apresenta uma pesquisa sobre a importância de utilização de gêneros textuais variados no processo de letramento de crianças com Síndrome de Down. A pesquisa foi realizada na Associação de Pais e Amigos dos Excepcionais (APAE), na cidade de Vitória da Conquista - BA. Tomamos como base o aporte teórico da Psicolinguística e práticas de letramento com utilização de gêneros textuais, considerando os níveis de participação dos atores do contexto educacional e familiar. Além dos dados obtidos por meio dos questionários, foram feitas observações de aulas e análise do material empregado no contexto escolar. Os resultados indicam que alunos com Síndrome de Down alcançam níveis satisfatórios de letramento quando na sala de aula são orientados por docentes que usam material diverso e tiveram contato precocemente com materiais escritos no núcleo familiar.

PALAVRAS-CHAVE: Gêneros textuais; letramento; psicolinguística; síndrome de down.

\section{Introdução}

Essa pesquisa tem como principal foco investigar como os meios escolar e familiar contribuem para o processo de letramento de crianças com Síndrome de Down e de como a utilização de gêneros textuais variados pode auxiliar nesse processo. $\mathrm{O}$ artigo está dividido em quatro seções. A primeira apresenta uma breve discussão sobre a importância de se

\footnotetext{
* Professora Titular da Universidade do Estado da Bahia (Uneb). Pós-Doutorado em Linguística pela University of Cambridge, Reino Unido e pela Universidade Federal Fluminense, Rio de Janeiro. Doutora em Linguística pela Universidade Estadual de Campinas (Unicamp).

** Doutora em Letras pela Pontifícia Universidade Católica do Rio Grande do Sul (Puc-RG). Professora Adjunta da área de Linguística da Universidade do Estado da Bahia (Uneb).
} 
utilizar teorias linguísticas nas práticas docentes. A segunda discute a conceituação de letramento e de como a utilização de variados gêneros textuais pode contribuir para uma qualificação do trabalho docente com alunos de Síndrome de Down (SD). Na terceira apresentamos a pesquisa de campo, bem como a análise dos dados coletados. E na última seção são apresentadas as Considerações Finais.

\section{As teorias linguísticas e a questão do ensino}

É recente a constituição da linguística enquanto ciência, tendo um método e objeto de estudo próprios. Como seu objeto, a língua, pode ser visto a partir de diferentes olhares e perspectivas, temos hoje variadas correntes linguísticas, com grande multiplicidade de concepções acerca da língua, o que traz como resultado diferentes possibilidades de abordar esse único objeto. Essas diferentes perspectivas teóricas de investigação linguística podem beneficiar processos práticos de sala de aula, ou, em outras palavras, o ensino de língua pode tomar como base diferentes arcabouços teóricos, que se complementam, para promover um ensino de qualidade.

Mas como modelos linguísticos podem serem aplicados ao ensino de língua? Seria possível aplicar conhecimentos teóricos de investigação linguística na prática de sala de aula? Essas são reflexões que, nos últimos anos, vem sendo discutidas por pesquisadores e professores.

É natural que em qualquer tipo de abordagem que estejamos desenvolvendo na sala de aula e que envolva trabalho com a linguagem, acabamos utilizando nosso conhecimento teórico sobre a língua, bem como as noções teórico-metodológicas dessa ou daquela corrente de estudo linguístico. Diante disso, sabemos que existem diferentes recortes e olhares sobre os variados aportes teóricos de ensino-aprendizagem envolvendo linguagem, visto que nosso objeto de estudo, a língua, é plural e multifacetado. Nesse trabalho delimitamos como aporte teórico questões relacionadas ao Letramento e aos Gêneros Textuais e de como esses últimos podem, intercalados com conhecimentos teóricos da Psicolinguística, ser importantes nas práticas escolares de crianças com Síndrome de Down. 
Na próxima seção, trataremos do conceito de Letramento e das possibilidades de ampliação do nível de letramento dos educandos utilizando na sala de aula variados gêneros textuais.

\section{O conceito de letramento e sua interação com as práticas sociais}

Letramento é um fenômeno intrinsecamente ligado às práticas sociais e não deve ser confundido com o processo de alfabetização, apesar de estarem imbricados. O conceito de letramento abrange uma visão ampliada da aquisição das habilidades de leitura e escrita como forma de inserção dos sujeitos nas práticas sociais que requerem a compreensão do código escrito, a capacidade de ler e escrever e é tomado como algo mais complexo do que apenas codificar e decodificar o texto. Nesse aspecto, pode-se dizer que o conceito de letramento complementa o de alfabetização.

A alfabetização, enquanto apropriação do sistema de escrita alfabética e de leitura, inicia-se normalmente na infância, no momento em que a criança é inserida no universo escolar e, com isso, a habilidade leitora vai progredindo ao longo dos anos escolares e é um processo que, de certo modo, se prolonga por toda a vida com a necessidade de as pessoas sempre agregarem conhecimentos em suas práticas sociais, o que proporciona o letramento ao preparar o indivíduo para os usos sociais da leitura e da escrita.

Para Soares (1999, p. 03), letramento é o “estado ou condição de quem não só sabe ler e escrever, mas exerce as práticas sociais de leitura e escrita que circulam na sociedade em que vive, conjugando-as com as práticas sociais de interação oral”. Estar alfabetizado significa ir além do processo de codificar e decodificar textos, significa também saber usar as funções da escrita e da leitura em diferentes contextos, utilizando essas funções de forma eficaz em situações concretas de interação. Letramento indica saber usar as habilidades dos códigos da escrita e da leitura no contexto e prática sociais. Mas isso não significa que só há letramento quando há alfabetização. A criança, mesmo que ainda não alfabetizada, muitas vezes, demonstra ter habilidades de letramento, como, por exemplo, ao contar histórias 
com características da escrita, tendo introdução, desenvolvimento, conclusão, discurso com sequenciação lógica.

Barton e Hamilton (1998) assumem que o letramento é uma prática cultural, sócio e historicamente estabelecida, que permite ao indivíduo apoderar-se das suas vantagens e assim participar efetivamente e decidir, como cidadão do seu tempo, os destinos da comunidade à qual pertence e às tradições, hábitos e costumes com os quais se identifica. De fato, uma visão ampla do significado do letramento abrange dimensões individuais, bem como cognitivas e sociais. Segundo Jones Diaz e Makin (2005, p. 04):

Letramento como prática social envolve um fenômeno social e cultural mais que resultado cognitivo. Isto implica considerar as atitudes, sentimentos, expectativas, valores e crenças de todos os participantes (crianças, famílias, professores, gestores e membros da comunidade) que exercem papel central no processo de letramento.

Nesse sentido, o letramento social assume a leitura e a escrita como práticas sociais que variam com o contexto e o uso. Para Kleiman (2006, p. 45), o letramento configura-se "como as práticas sociais de leitura e de escrita adquiridas por uma coletividade". Tfouni (2010, p. 31) afirma que o letramento “é um processo de natureza sócio-histórica”. Portanto, é construído ao longo da vida do indivíduo e inserido no contexto social, abrangendo o meio familiar, a comunidade em que a pessoa está inserida, além da agência de letramento tradicional que é a escola.

Para que se atinjam níveis elevados de letramento, dois elementos básicos são necessários: (i) eventos e (ii) práticas de letramento. Tem-se um evento de letramento sempre que as pessoas se organizam em torno de textos escritos em situações que envolvam a compreensão desses textos. Tais eventos são "situações em que a língua escrita é parte integrante da natureza da interação entre os participantes e de seus processos de interpretação" (HEATH, 1982, p. 93). Ocorrem em diferentes esferas sociais, como escola, lar, organizações empresariais, igreja, isto é, em contextos nos quais se busque, em conjunto, ler e compreender textos escritos para as mais variadas finalidades. 
Heath (1982, p. 93) considera que o evento de letramento é uma ferramenta conceitual utilizada para examinar, dentro de comunidades específicas da sociedade moderna, as formas e funções das tradições orais e letradas e as relações coexistentes entre a linguagem falada e escrita. Um evento de letramento é qualquer situação em que um suporte torna-se parte integrante de uma interação entre participantes e dos seus processos interpretativos.

As práticas de letramento, por sua vez, demarcam o comportamento exercido pelos participantes de um evento e as concepções sociais e culturais que o configuram, determinam sua explicação e dão sentido aos usos da leitura e da escrita naquela situação particular. A importância do letramento para a inclusão do indivíduo nas práticas sociais que requerem a leitura e a escrita é tanta, que o Programa Internacional de Avaliação de Estudantes (PISA) estabeleceu marcos referenciais em termos de letramento com o objetivo de nortear o trabalho docente.

No processo de letramento, o papel dos agentes de letramento é fundamental para articular interesses partilhados pelos aprendizes, organizar um grupo ou comunidade para a ação coletiva, auxiliar na tomada de decisões sobre determinados cursos de ação, interagir com outros agentes (outros professores, coordenadores, pais da escola) de forma estratégica e modificar e transformar seus planos de ação segundo as necessidades em construção do grupo (KLEIMAN, 2006).

Atuar como agente propiciador de letramento requer do professor uma postura diante do desafio de mediar as situações de leitura, atuar como consultor e animador do processo, exercendo uma influência construtiva e planejando estrategicamente as ações para atingir os objetivos propostos para a atividade de leitura.

A escolha dos materiais de leitura adequados ao nível de letramento e de interesse dos alunos é outro fator relevante para o sucesso do processo de letramento. Também o espaço físico escolar deve ser estruturado e instrumentalizado para abrigar tais eventos. Um ambiente da sala de aula motivador, com livros e elementos visuais que remetam à leitura contribui para as práticas de leitura. 
Além do ambiente motivador da sala de aula, a escola necessita de uma biblioteca com um acervo diversificado de títulos que atendam às necessidades, aos níveis de compreensão e interesses dos alunos. Nessa perspectiva, Bortone e Ribeiro (2000) sugerem que haja um material de leitura disponível e de qualidade.

No entanto, o letramento também acontece fora do ambiente escolar, em outras esferas sociais, como no núcleo familiar. Se a criança tem contato com materiais escritos desde muito cedo, tem mais condições de adquirir o hábito de leitura e de alcançar níveis elevados de letramento. Heath (1982) realizou uma pesquisa longitudinal na qual comparou as práticas letradas em três famílias de classes sociais distintas. As famílias pertencentes à classe privilegiada financeiramente disponibilizavam materiais escritos e contavam histórias para as crianças que demonstraram mais facilidade no processo de aquisição da leitura e da escrita ao adentrar no ambiente escolar. Na família de classe menos favorecida de pais imigrantes não foram identificados eventos de letramento e as crianças desse contexto sentiram mais dificuldade na leitura e escrita escolar.

Constata-se que "os benefícios de um ambiente familiar rico em eventos de letramento resulta em maior sucesso no desenvolvimento inicial da leitura e, consequentemente, em maior sucesso nas primeiras séries escolares" (WELLS, 1986, p. 26-27). Terzi (1995) argumenta que a exposição da criança a frequentes leituras de livros a leva a desenvolverse como leitora já no período pré-escolar. Esse desenvolvimento contribui, sem dúvida, para uma maior facilidade em acompanhar o ensino proposto pela escola, o que resulta em maior sucesso.

A escola tem a função de formar o leitor competente e, para que isso aconteça, deve oportunizar a efetiva prática de leitura, fundada em uma gama diversificada de tipos de textos e gêneros textuais, tema que será exposto na próxima seção 


\section{A importância dos gêneros textuais nas práticas de letramento}

A enorme variedade de textos expostos nas esferas sociais tem finalidades e formatos diferentes, pertencentes a tipos de textos e gêneros diversos. Incluem-se textos literários, não-literários, jornalísticos, informativos, didáticos, instrucionais, virtuais. Essa multiplicidade requer habilidades sofisticadas de compreensão que envolvem a identificação da superestrutura textual (narração, descrição, dissertação, entre outras), do vocabulário, do gênero em que se enquadram, dos implícitos presentes nos textos. A compreensão de um texto requer o reconhecimento de dois dados importantes: que o significado de uma parte do texto não é autônomo, depende de outras partes com que se relaciona e o significado global resulta de uma combinação que gera os sentidos. No Quadro 2, apresentamos a diversidade de textos de uso social.

Quadro 1 - Diversidade de textos de uso social

Textos da vida cotidiana: cartas, listas, receitas, textos instrucionais, rótulos.

Textos literários: contos, lendas, crônicas, poemas, músicas.

Textos de transmissão oral: literatura de cordel e provérbios.

Textos de meios de comunicação: jornal (notícias, anúncios, tabelas, quadrinhos, entrevistas, gráficos).

Textos de informação científica: textos informativos, científicos de diferentes fontes (fascículos, enciclopédias, revistas, livros didáticos entre outros), biografia, dicionário.

Fonte: Durante (1998, p. 52)

O ensino de leitura explorando gêneros textuais variados em sala de aula auxiliam os educandos a ampliarem seu nível de letramento. Uma vez que este é voltado para as práticas sociais, perpassa tanto o discurso oral quanto o discurso escrito, focalizando os usos e funções da leitura e da escrita.

Bakhtin (1999) foi o primeiro a utilizar o termo "gêneros" em um sentido mais abrangente, incluindo textos que empregamos nas situações cotidianas de comunicação. 
Para ele, todos os textos que produzimos, sejam orais ou escritos, apresentam características relativamente estáveis, tenhamos ou não consciência delas. Tais características configuram diferentes textos ou gêneros textuais ou discursivos, que podem ser caracterizados por três aspectos básicos coexistentes: o tema, o modo composicional (a estrutura) e o estilo (usos específicos da língua). Os Gêneros são entidades sócio-discursivas e formas de ação social incontornáveis em qualquer situação comunicativa (MARCUSCHI, 2002).

Segundo Marchuschi (2008), os gêneros são realizações linguísticas concretas definidas por propriedades sócio-comunicativas e retratam a sociedade e seus modos de ser. O conceito de gênero não se limita a "expressões estilísticas e organizacionais" (BAZERMAN, 2006, p. 23). Os textos, por sua vez, são "manifestações verbais mediante a língua" (MARCUSCHI, 2002, p. 23).

Em um contexto de interação verbal, a escolha dos gêneros não se dá de maneira totalmente instintiva, pois considera o conjunto de elementos extralinguísticos que interferem na escolha e que advém da própria situação comunicativa: o interlocutor, o assunto tratado, o propósito da conversa. Isso determina a escolha do gênero adequada a cada situação (ROJO, 2012).

Bakhtin (1999) e Bronckart (1999) defendiam a concepção de que a comunicação somente seria possível a partir de gêneros textuais, também colocados como gêneros discursivos por Bakhtin (1999). A língua é compreendida, dessa maneira, como um processo social, histórico e cognitivo. Ora, se a comunicação se dá a partir dos gêneros e a língua se estrutura social e historicamente, é possível concluir que os gêneros textuais estão presentes no cotidiano das pessoas, de forma geral.

Os gêneros que atuam em sala de aula, por sua vez, não são apenas uma "repetição ritual de proposições padronizadas" (BAZERMAN, 2006, p. 31). Se eles costumam estar restritos a isso, deve-se analisar a forma como estão sendo trabalhados nas atividades em sala de aula, uma vez que é de extrema relevância colocar os alunos em contato com o maior número possível de gêneros textuais que existem na sociedade, para incluílos nos processos de compreensão e transformação desta. 
Os gêneros são variados e vão desde as cartas ao texto científico, além de contos, fábulas, notícias, mapas, cartazes, gráficos, e-mails, receitas culinárias, manuais diversos, ofícios, charges, dentre outros. A leitura e a escrita dessas variedades de textos exercitam a habilidade cognitiva dos alunos e ampliam a sua capacidade de expressão linguística, ou seja, amplia o seu grau de letramento, na verdade, letramentos.

A análise das práticas de letramento empregando gêneros textuais variados abordados no âmbito escolar destaca-se como de significativa relevância, posto que trabalhar pedagogicamente com a leitura e a escrita, nesta perspectiva, significa reconhecer a variedade de textos que circulam na sociedade e possibilitam as interações sociais, portanto, abre o leque para que os discentes tenham uma participação efetiva e ampla na sociedade.

De fato, formar um leitor competente supõe formar alguém que compreenda o que lê; que possa aprender a ler também o que não está escrito, identificando elementos implícitos; que estabeleça relações entre o texto que lê e outros textos já lidos; que saiba que vários sentidos podem ser atribuídos a um texto; que consiga justificar e validar a sua leitura a partir da localização de elementos discursivos que permitam fazê-lo (BRASIL, 1997).

A leitura de materiais escritos requer a compreensão dos signos que articulam tanto a linguagem literal como a figurada. Os signos constituem-se num todo organizado de sentido, que é o texto, manifestado sob diferentes formas de expressão. A leitura requer do leitor compreender a organização interna (coesão e coerência) e os recursos que produzem sentido.

Para Kintsh (1998), a compreensão de um texto pode ser superficial quando se limita a extrair o significado contido no texto e profunda quando corresponde a interpretar ou elaborar um modelo de situação tratada no texto. Miguel (2012) acrescenta a ideia da compreensão crítica e reflexiva, quando o leitor repara na existência de uma contradição entre o que se diz em dois textos diferentes, ou entre o que pensava e o que se diz no texto. 
Os estudos desenvolvidos pela Psicolinguística resultaram em descobertas importantes sobre a compreensão. A evolução de tais estudos resultou num modelo contemporâneo de compreensão da leitura estruturado por Giasson (2000), que mostra a intersecção entre o leitor, o texto e o contexto, conforme demonstra a figura 1.

Figura 1 - Modelo contemporâneo de compreensão da leitura

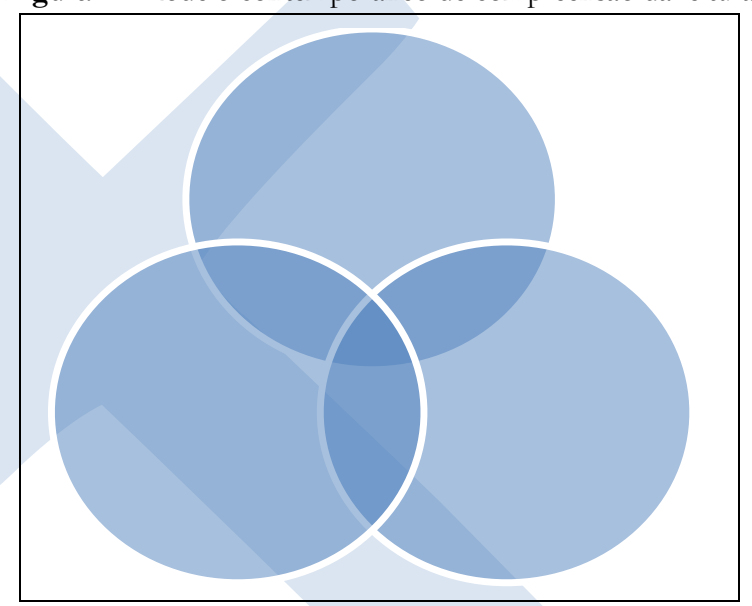

Fonte: Giasson (2000, p. 21).

Nesse modelo, a parte que corresponde ao leitor abrange as estruturas do sujeito e os processos de leitura que ele utiliza. Globalmente, as estruturas têm relação com os conhecimentos e atitudes do leitor, enquanto os processos referem-se às habilidades a que recorre durante a leitura. O elemento texto abarca três aspectos principais: a intenção, a forma/estrutura e o conteúdo. Referindo-se ao primeiro aspecto - a intenção - parte-se do princípio de que nenhum texto é neutro, sempre carrega a intenção do autor, o que ele pretende expressar. A estrutura remete à forma como o autor organizou as ideias no texto e o conteúdo engloba os conceitos, conhecimentos e vocabulário escolhidos pelo autor. 
O contexto inclui os elementos que não fazem parte do texto e que não dizem respeito diretamente às estruturas ou processos de leitura, mas que interferem na compreensão do texto. Podem-se diferenciar três tipos de contextos: o psicológico (objetivo da leitura, interesse pelo texto), o contexto social (interferências de professores, de colegas) e o contexto físico (o ambiente, luminosidade, tempo disponível para a leitura, silêncio ou barulho).

De posse desse conhecimento, o professor pode elaborar atividades que auxiliem os alunos a compreenderem o que leem, tornando-se leitores conscientes, capazes de desvendar os implícitos do texto, a linguagem simbólica, opiniões, intenções presentes no texto.

A exploração de textos se dá de várias maneiras diferentes, dentre elas, visual, auditiva ou falada. Todos os tipos de leitura devem ser explorados em sala de aula pois o aluno deve ter contato com os vários gêneros e tipos textuais. Além dos materiais utilizados, como os diversos tipos de textos, necessários também para contemplar os variados interesses dos alunos, a sala de aula deverá estar repleta de formas de apresentação de textos para que eles tenham acesso aos seus diversos tipos. O aprendizado também está muito ligado à leitura: por mais que se insista no pensamento de que leitura é ferramenta de trabalho do professor de língua portuguesa, na escola todas as demais disciplinas se valem da leitura para a condução das atividades de ensino e aprendizagem, devendo, portanto, explorar o seu aprendizado de modo eficiente.

Durante o trabalho com textos, o professor não deve reprimir seu aluno quanto às suas conclusões em relação ao que compreendeu, e sim, usar o diálogo para aproveitar a situação com o intuito de desenvolver a competência leitora do aluno e proporcionar momentos agradáveis de exploração textual. Existem alunos que se expressam bem, outros às vezes têm dificuldades em compreender o que leem, como também há alunos com boa capacidade de compreensão, mas que não conseguem traduzir o que entenderam. Essas situações acontecem com frequência na escola. Em relação a isso, Cagliari (1998) afirma que não se deve concluir que uma criança lê bem, enquanto uma outra lê mal; todas leem 
de maneiras diferentes. E todas as interpretações devem ser consideradas e exploradas em sala de aula desde que não fujam totalmente à lógica do texto.

As dificuldades de compreensão dos textos escolares trazem inquietação dos professores comprometidos com a educação de qualidade. Se o aluno não compreende o que lê, vários fatores concorrem para isso, pode ser vocabulário deficiente, atenção, emoção. O professor então, deve, além de conhecer seus alunos para planejar aulas que chamem atenção com textos interessantes e motivadores, deve também apropriar-se de saberes que o ajudem a diagnosticar as causas do problema.

O letramento não deve ser encarado como redentor para as pessoas, principalmente as minorias excluídas, seja por situação econômica ou por serem tidas como diferentes como no caso das pessoas com SD. No entanto, ele é condição necessária, embora não suficiente, para a inserção das pessoas nas práticas sociais que requerem a leitura e auxiliam no empoderamento e na legitimação das pessoas no exercício pleno da cidadania porque instrumentaliza para a compreensão de aspectos da realidade como a busca por direitos, possibilidade de mobilidade social, conscientização de desigualdades, apropriação de saberes diversos. Na próxima seção, apresentaremos dados de letramento de pessoas com SD, tema pouco explorado ainda por pesquisas atualmente.

\section{O letramento na Sindrome de Down}

A Síndrome de Down (SD) é definida como sendo um quadro genético caracterizado pela trissomia de cromossomo 21 ou por mosaicismo, o seu portador possui alterações que caracterizam esta síndrome, tais como: malformações cardíacas, déficit no desenvolvimento neuropsicomotor e hipotonia (baixo tônus muscular) corporal global e hiperatividade, dificuldades de aprendizagem (CUNNINGHAM, 2008, p. 82).

A SD é geralmente diagnosticada ao nascimento em razão da presença de uma série de alterações fenótipas, que podem ser observadas já no feto, que são a presença de prega palmar única, clinodactilia, defeitos do septo cartilaginoso e baixo comprimento do feto. Já após o nascimento são observados em crianças com esta síndrome, aspectos tais como: 
branquicefalia, fissuras palpebrais com inclinação superior, pregas epicânticas, base nasal achatada, hipoplasia da face (SOUZA, 2003).

As pessoas com SD possuem características bem marcantes “...hiperlassidão, hipotonia, desenvolvimento mais lento, dificuldades de aprendizagem e há modificações cerebrais semelhantes à Demência de Alzheimer" (CUNNINGHAM, 2008, p. 82).

O desenvolvimento da linguagem em crianças com SD é atípico, ocorre de forma mais vagarosa em comparação com as crianças de desenvolvimento típico e esse fato acarreta problemas na interação sociocomunicativa e no desenvolvimento das atividades escolares principalmente no que diz respeito às habilidades de leitura e escrita.

Um dos maiores desafios na educação de crianças com SD é fazer com que a mesma seja mais autônoma na sala de aula, fazendo que adquira regras da vida social para que possa se conduzir sem incomodar o grupo em que está inserida (BUSCAGLIA, 2002).

A estimulação precoce da psicomotricidade da criança com SD potencializa o desempenho dela na fase de escolarização quando entra em contato pela primeira vez com o código escrito.

Entende-se a leitura e a escrita como aprendizagens fundamentais para a inserção dos sujeitos em contextos letrados dada a constatação que o mundo globalizado demanda níveis cada vez mais elevados de letramento. Assim, é necessário dar oportunidade aos que não possuem as habilidades de leitura e escrita, um aprender continuado. Não obstante, é preciso reconhecer que não somente o domínio do código da leitura e da escrita, mas também a competência como leitor e escritor de seu próprio texto, de sua própria história, de sua passagem pelo mundo são relevantes.

Mas não basta que o indivíduo seja apresentado ao universo das letras apenas pelo processo de alfabetização. Ser alfabetizado não garante que a pessoa seja capaz de realizar as diferentes ações que envolvem competência em leitura e escrita. É necessário ir além da codificação e decodificação, ou seja, compreender textos escritos e escrever de forma a atender as necessidades do dia a dia nos espaços escolares e no trabalho. 
Ocorre que as crianças com SD ao entrarem para a escola na fase de alfabetização nem sempre obtém o resultado esperado de aprender a ler e a escrever. Dentre os possíveis motivos, segundo Luís (et al., 2008), tais alunos são muitas vezes recebidos em sala de aula sem um atendimento especializado que possa promover uma alfabetização eficaz que os ajude a se inserirem na sociedade em que vivem, escrevendo, lendo, interpretando textos e, por consequência, facilitando sua atuação no mercado de trabalho.

Um fator de fundamental importância para a alfabetização da criança Down é desenvolver a habilidade da consciência fonológica. De acordo com Brites (2018):

Consciência fonológica é a habilidade que nós temos em manipular os sons de nossa língua. É a capacidade de percebermos que uma palavra pode começar ou terminar com o mesmo som. Além disso, é quando sabemos que existem também termos grandes e pequenos; e que há frases (e uma segmentação nessas orações).

A consciência fonológica refere-se tanto à consciência de que a fala pode ser segmentada quanto à habilidade de manipular tais segmentos. A importância da consciência fonológica para o processo de aquisição de leitura e escrita tem sido bastante reconhecida. De fato, um grande número de estudos tem relatado que a habilidade de estar conscientemente atento aos sons da fala se correlaciona com o sucesso na aquisição da leitura e escrita. Além disso, uma série de estudos tem relatado que procedimentos sistemáticos para desenvolver consciência fonológica facilitam a aquisição da leitura e da escrita (CAPOVILLA \& CAPOVILLA, 2000).

Desenvolver essa habilidade auxilia na alfabetização. Porém, não basta alfabetizar somente. O ideal é que o aluno compreenda o que lê, reflita sobre o texto, escreva com coerência e coesão, isso implica em usos sociais da leitura e da escrita - o letramento. Letramento e alfabetização são complementares.

As habilidades mais aprofundadas de leitura e escrita representam portanto, o letramento, conceito forjado nos países de língua inglesa para suprir as dificuldades de pessoas alfabetizadas que não conseguiam compreender e escrever textos. 
É necessário ultrapassar a mera decodificação/decifração e a interpretação literal dos textos e isso implica apoderar-se do letramento que Tfouni (2010, p. 11) "considera a dimensão político-ideológica da leitura e da escrita, reivindicando ações educativas para além da decifração literal". Portanto, o letramento é construído ao longo da vida do indivíduo e inserido no contexto social abrangendo o meio familiar, a comunidade em que a pessoa está inserida, além da agência de letramento tradicional que é a escola.

Atingir níveis mais elevados de letramento é de fundamental importância para os indivíduos com SD para auxiliar na construção de conhecimentos, à sua formação como cidadão atuante e engajado na dinâmica atual.

De acordo com Troncoso e Cerro (2004, p. 22) um método de leitura que atenda às especificidades das crianças com SD pode ser bem bem-sucedido se: (a) ajusta-se às capacidades cognitivas da criança com SD; (b) tem em conta as características de cada criança; (c) estimula e facilita o desenvolvimento cognitivo posterior: o exercício da memória a curto e a longo prazo, a autonomia pessoal na aquisição de conceitos e a capacidade de correlação e (d) facilita o desenvolvimento da linguagem expressiva.

É importante lembrar que o ato de letrar especialmente pessoas tão especiais como as crianças com SD é uma tarefa que exige do professor determinação, conhecimento, paciência, perseverança muita didática e sensibilidade, pois tem também o objetivo de estimular o desenvolvimento pessoal, social e cognitivo do aluno, garantindo-lhe o direito de vOz e ampliando seus recursos para a reflexão (cf. FEISTAUER, 2014, p. 81).

$\mathrm{O}$ aluno com SD, embora seja capaz de alcançar resultados positivos no rendimento escolar, tem um aprendizado que ocorre de forma mais lenta. Sendo assim, é necessário um estímulo muito maior por parte do professor. Os conteúdos devem ser enriquecidos com metodologias inovadoras que venham a despertar no aluno a vontade de aprender, levando em consideração que geralmente esse aluno possui dificuldades na atenção. As atividades recreativas são metodologias que devem ser muito exploradas pelos professores, pois despertam no aluno o desejo e a motivação (CARVALHO et al, 2015). 
Metodologias inovadoras que envolvam as habilidades de leitura e de escrita são bem-vindas para proporcionar o letramento das crianças Down. Materiais coloridos, livros ilustrados, canções, jogos, quadrinhos, animes são estratégias que podem funcionar muito bem na construção de saberes dos alunos com SD.

\section{Dados coletados}

Este artigo resulta de pesquisa realizada na Associação de Pais e Amigos dos Excepcionais (APAE), localizada na cidade de Vitória da Conquista - BA, cujo objetivo é analisar os níveis de letramento de crianças com Síndrome de Down com base no aporte teórico da Psicolinguística e no conceito de letramento considerando os níveis de participação dos atores do contexto educacional e familiar, utilizando gêneros textuais. Trata-se de um estudo qualitativo de corte transversal. O projeto de pesquisa foi submetido ao Comitê de Ética da PUC-RS tendo sido aprovado com no 1133691210000 5336. Para a coleta dos dados foram aplicados questionários semiestruturados. As mães responderam a um questionário, com questões envolvendo aspectos socioeconômicos, relativos à saúde e a hábitos de leitura das crianças e adolescentes. Para identificá-las usamos a expressões M1, M2, M3, M4 e M5.

Além dos dados por meio dos questionários, foram feitas observações de aulas e análise do material empregado nas aulas de leitura. Os participantes da pesquisa foram: cinco mães, quatro educadoras sendo três professoras, e uma orientadora educacional e cinco alunos com SD.

As crianças e adolescentes tinham idades cronológicas variadas entre 8 e 14 anos, duas do sexo feminino e três do sexo masculino, encontram-se alfabetizados ou semialfabetizados e frequentavam a APAE. Três alunos residem na zona rural do município de Vitória da Conquista e pertencem a famílias de baixa renda tendo como base de sustento o benefício do INSS recebido pelo aluno e a bolsa-família. Dois alunos residem na zona urbana e são de classe média. 
Foram observadas as práticas de leitura: os textos escolhidos para o trabalho, a abordagem feita com os textos, a sequência didática para verificar a compreensão dos textos, os gêneros textuais utilizados, as estratégias de leitura (antecipação, inferência e verificação) demonstradas pelos alunos (FEISTAUER, 2014, p. 86).

Das cinco mães participantes da pesquisa, três são semialfabetizadas (Mãe 1, Mãe 2 e Mãe 3); uma possui Ensino Médio completo (Mãe 4) e a Mãe 5 possui nível superior com Pós-graduação em Letras, área de concentração Literatura.

\section{Resultados encontrados}

Em relação à formação específica para trabalhar com alunos especiais, das três professoras participantes da pesquisa, somente P1 possui formação específica na área de SD um curso de Pós-graduação de um ano na área de Educação Inclusiva. Sobre as práticas de leitura aplicadas aos alunos com SD as professoras relataram apresentar variados gêneros para a leitura e compreensão textual, mas que o gênero preferido é o conto de fadas. Elas afirmaram que os alunos com SD compreendem textos adequados a seu nível de desenvolvimento (FEISTAUER, 2014).

A orientadora educacional possui Graduação em Pedagogia (modalidade EAD). Possui formação específica na área de SD - Pós-Graduação em Educação Inclusiva. Também possui em seu currículo cursos de atualização e seminários com profissionais especialistas em SD. Ela destacou também que são trabalhados variados gêneros textuais (filmes, propagandas, histórias em quadrinhos, músicas e obra de arte).

As mães responderam a questões sobre a gestação, o desenvolvimento motor e da linguagem e hábitos de leitura no ambiente doméstico. Das cinco mães, a M1 não possui livros em casa e não lê para o filho; isso se dá pelo fato de ser semialfabetizada, Pelas respostas dadas, quatro mães relataram que há momentos de leitura com familiares, discussão com as crianças sobre a compreensão do que é lido, porém isso não ocorre sistematicamente em todas as famílias investigadas. 
A respeito da compreensão da leitura, apenas a M1 afirmou que o filho não compreende, as outras quatro afirmaram que os filhos compreendem o que é lido para eles. M4 e M5 afirmaram que os filhos, além de compreenderem, recontam a história e relembram personagens e falas.

O gênero textual preferido relatado por quatro mães foi o conto de fadas, o que corrobora com as respostas das professoras. Apenas o aluno mais velho (com idade cronológica de 14 anos) preferia o gênero aventura. O conto de fadas é um gênero narrativo que instiga a imaginação das crianças apresentando amores verdadeiros, a luta entre o bem e o mal e valores perenes do ser humano.

O conto de fadas auxilia no letramento porque é um gênero que agrada e faz com que os alunos leiam, apreciem, interpretem a história. Uma boa história sempre desperta o interesse das crianças. Ela entra na trama por uma espécie de portal que o autor abre como um convite ao pequeno leitor para que atravesse e adentre nos cenários e mundos fictícios narrados (FEISTAUER, 2014, p. 91). A contação de histórias, segundo Cosson (2014), é uma estratégia pedagógica que usualmente entra na escola como parte da preparação das crianças para a leitura.

Na APAE escola-clínica, situada em Vitória da Conquista, campo empírico desta pesquisa, foram constatadas diversas práticas e eventos de letramento, adequadas às especificidades do público alvo.

Heath (1982, p. 93) considera que o evento de letramento é uma ferramenta conceitual utilizada para examinar, dentro de comunidades específicas da sociedade moderna, as formas e funções das tradições orais e letradas e as relações coexistentes entre a linguagem falada e escrita. Um evento de letramento é qualquer situação em que um suporte torna-se parte integrante de uma interação entre participantes e dos seus processos interpretativos.

Já as práticas de letramento são atividades humanas concretas. Envolvem não somente o que as pessoas fazem, mas o que elas fazem a partir do que sabem e o que elas pensam sobre o que fazem. Também é levado em conta como essas pessoas "constroem" 
o valor e a ideologia que já permeiam esse acontecimento e que estão subjacentes a essas ações (BAYNHAM, 1995, p. 39).

Com relação ao uso de tecnologias, as Mães 1, 2 e 3 não possuem computador e nem internet em casa. A Mãe 4 e Mãe 5 responderam que possuem computador e internet em casa e que os filhos navegam na internet. A Mãe 4 afirmou que a filha (de 8 anos) assiste a vídeos de músicas e brinca com jogos na internet. A Mãe 5 relatou que o filho (de 14 anos) assiste a vídeos (histórias, animes) e que ela conta histórias fazendo o acompanhamento através da internet (FEISTAUER, 2014).

A oportunidade do contato com outros formatos de textos que não os lineares como é o caso de materiais da internet auxilia as crianças para a compreensão de textos, narrativas, histórias mediadas pela tecnologia, o que caracteriza o multiletramento (FEISTAUER, 2014, p 89).

$\mathrm{Na}$ perspectiva dos multiletramentos, o ato de ler envolve articular diferentes modalidades de linguagem além da escrita, como a imagem (estática e em movimento), a fala e a música. Nesse sentido, refletindo as mudanças sociais e tecnológicas atuais, ampliam-se e diversificam-se não só as maneiras de disponibilizar e compartilhar informações e conhecimentos, mas também de lê-los e produzi-los (ROJO, 2012).

O multiletramento para os Downs traz uma nova visão da leitura dinamizada pelas imagens aliadas ao texto tendo como pano de fundo mensagens que podem ser enquadradas em variados gêneros textuais como o texto narrativo, músicas que de qualquer modo possuem significação, expressam ideias que podem auxiliar no desenvolvimento da compreensão desses indivíduos (FEISTAUER, 2014).

Os resultados da pesquisa revelam que três das cinco mães são semialfabetizadas e não leem para os filhos, nem possuem livros em casa. Duas famílias possuem maior escolarização e promovem eventos de letramento com as crianças e adolescentes com SD. As professoras realizam práticas e eventos de letramento nas aulas observadas e na oficina de linguagem. 
Os dois alunos com SD cujas famílias são letradas compreendem, questionam, recontam e dramatizam textos; os três alunos cujas famílias não são letradas conseguem compreender e recontar histórias. A partir dessas verificações, pode-se concluir que os alunos com SD podem alcançar níveis satisfatórios de letramento quando bem orientados por professoras comprometidas com o trabalho e mais ainda se tiverem o contato com materiais escritos precocemente com a família.

\section{Considerações finais}

Atualmente tem ocorrido muitas discussões entre estudiosos e demais pesquisadores e professores de língua materna sobre a exigência da sociedade letrada em requerer cada vez mais níveis satisfatórios de letramento.

Se o letramento é importante para a inserção dos indivíduos com desenvolvimento tipo nas práticas sociais letradas, é ainda mais relevante para pessoas com necessidades educativas especiais, como é o caso da Síndrome de Down. Isso porque, devido a sua condição, são vistas como diferentes e muitas vezes sofrem discriminação por parte de pessoas desinformadas e preconceituosas.

Mas não basta alfabetizar, ensinar a codificar a escrita e decodificar a leitura, é preciso que o aluno compreenda o que lê, produza textos escritos coerentes, acesse informações, faça escolhas linguísticas, ou seja, desenvolva o letramento. Materiais coloridos, livros ilustrados, canções, jogos e gêneros textuais diversificados e adequados a idade e desenvolvimento são bem-vindos para auxiliar na aprendizagem da criança com SD.

Os professores necessitam, além de formação especifica para trabalharem com o aluno Down, também uma dose de paciência, atenção e carinho para trazer harmonia ao ambiente educativo nos momentos de aprendizagem. Os alunos com SD podem atingir níveis mais avançados de letramento desde que sejam expostos a práticas e eventos de letramento significativos para eles. O letramento é uma porta aberta para a inserção dos Downs no meio social como sujeitos capazes de exercer plenamente a cidadania. 


\section{LITERACY PRACTICES IN DOWN SYNDROME: THE IMPORTANCE OF TEXTUAL OF TEXTUAL GENRES}

ABSTRACT: This paper presents a research about the importance of using varied textual genres in the literacy process of children with Down Syndrome. The research was conducted at the Association of Parents and Friends of the Exceptional (APAE), in the city of Vitória da Conquista - BA. We take as base the theoretical support of Psycholinguistics and literacy practices using textual genres, considering the levels of participation of the actors in the educational and family context. In addition to the data obtained through the questionnaires, observations were made of classes and analysis of the material used in the school context. The results indicate that students with Down Syndrome achieve satisfactory levels of literacy when in the classroom they are guided by teachers who use diverse material and had early contact with materials written in the family nucleus.

KEYWORDS: Textual genres; Literacy; Psycholinguistic; Down syndrome.

\section{REFERÊNCIAS}

BAKHTIN, M. Estética da criação verbal. São Paulo: Martins Fontes, 1999.

BARTON, D.; HAMILTON, M. Local Literacies: reading and writing in one community. London: Routledge, 1998.

BAZERMAN,C. Gêneros textuais, tipificação e interação. In: DIONÍSIO, A. P. ; HOFFNAGEL, J. J. (Orgs.). São Paulo: Cortez, 2006.

BORTONE, M. E.; RIBEIRO, O. M. Letramento e leiturização. In: SEMINÁRIOS DA UNIVERSIDADE DE UBERABA, 9; 10, 2001. Anais. Uberaba: Ed. Universidade de Uberaba, 2001. p. 65-67.

BRASIL. Ministério da Educação. Parâmetros Curriculares Nacionais (PCN). Brasília: MEC, 1997.

BRONCKART, J.-P. Atividade de linguagem, textos e discursos: por um interacionismo sociodiscursivo. Tradução Anna Rachel Machado. São Paulo: Educ, 1999.

BAYNHAM, M. Literacy practices: investigating literacy in social contexts. London: Longman, 1995.

BRITES, Luciana. Consciência Fonológica: por que ela é essencial para a alfabetização?. 2018. Disponível em: https://neurosaber.com.br/consciencia-fonologica-por-que-ela-eessencial-para-a-alfabetizacao/. Acesso em: 23 de agosto de 2019.

BUSCAGLIA, L. Os Deficientes e seus Pais: um desafio ao aconselhamento. 4.ed. Rio de Janeiro: Record, 2002.

CAGLIARI, L. C. Alfabetizando sem o ba-be-bi-bo-bu. São Paulo: Scipione, 1998. 
CAPOVILlA, A.; CAPOVILLA, F.C. Problemas de Leitura e Escrita. 2. ed. São Paulo: Memnon edições científicas, 2000.

CARVALHO, Graciely Thaiss de et al. O processo de alfabetização do aluno com síndrome de down na escola inclusiva nos anos iniciais do ensino fundamental. Revista Eletrônica do Curso de Pedagogia das Faculdades OPET . Dezembro de 2015.Disponível em: http://www.opet.com.br/faculdade/revista-pedagogia/pdf/n10/ARTIGO1.pdf. Acesso em: 23 de agosto de 2019.

COSSON, R. Círculos de leitura e letramento literário. São Paulo: Contexto: 2014.

CUNNINGHAM, C. Síndrome de Down: uma introdução para pais e cuidadores. Tradução Ronaldo Cataldo Costa. 3. ed. Porto Alegre: Artmed, 2008.

FEISTAUER, Cláudia Madalena. O letramento na síndrome de down: o papel da família e da escola. Tese de Doutorado PUC-RS. - Porto Alegre, 2014.

GIASSON, J. A compreensão na leitura. Portugal: Asa, 2000.

HEATH, S. B. What no bedtime story means: narrative skills at home and school. Language in Society, v. 11, p. 49-76, 1982.

LUIZ, Flávia Mendonça Rosa e; BORTOLI, Paula Saud De; FLORIA-SANTOS, Milena and NASCIMENTO, Lucila Castanheira. A inclusão da criança com Síndrome de Down na rede regular de ensino: desafios e possibilidades. Rev. bras. educ. espec. [online]. 2008, vol.14, n.3, pp. 497-508. ISSN 1413-6538. < http://www.producao.usp.

br/bitstream/handle/BDPI/11424/art LUIZ A inclusao da_crianca_com_Sindrome_de_2008.pdf?sequence=1\&isAllowed=y>. Acesso em: 26/08/2019.

JONES DIAZ, C.; MAKIN, L. Literacy as social practice. In: MAKIN, L.; DIAZ, J. (Eds.). Literacies in early childhood. Changing Views Challenging Practice. Sydney: Maclennan \& Petty, 2005. p. 3-14.

KINTSH, W. Comprehension. A paradigm for cognition. Cambridge: Canbridge University Press, 1998.

KLEIMAN, A. Processos identitários na formação profissional - O professor como agente de Letramento. In: CORRÊA, M.; BOCH, F. Ensino de língua: representação e letramento. Campinas, SP: Mercado das Letras, 2006.

MARCUSCHI, L. A. Gêneros textuais: definição e funcionalidade. In: DIONÍSIO, A. P. ; MACHADO, A. R.; BEZERRA, M. A. (Orgs.). Gêneros textuais \& ensino. Rio de Janeiro: Lucena, 2002. p. 19-36.

. Produção textual, análise de gêneros e compreensão. São Paulo: Parábola, 2008.

MIGUEL, E. S. Leitura na sala de aula: como ajudar os professores a formar bons leitores. Tradução Fátima Murad. Porto Alegre: Penso, 2012. 
ROJO, Roxane. Multiletramentos na escola. São Paulo: Parábola Editorial, 2012

SOARES, M. B. Português: uma proposta para o letramento. São Paulo: Moderna, 1999.

SOUZA, A. M. C. A Criança Especial: temas médicos, educativos e sociais. São Paulo: Roca, 2003.

TERZI, S. B. A oralidade e a construção da leitura por crianças de meios iletrados. In:

KLEIMAN, Â. B. (Org.). Os significados do letramento: uma nova perspectiva sobre a prática social da escrita. Campinas, SP: Mercado de Letras, 1995.

TFOUNI, Leda Verdiani (org.). Letramento, escrita e leitura. Campinas/SP: mercado das Letras, 2010.

TRONCOSO, M. V.; DEL CERRO, M. M. Sindrome de Down: leitura e escrita. Porto, Portugal: Porto, 2004.

WELLS, G. The meaning makers. Portsmouth, NH, Heinemann, 1986.

Recebido em: 25/07/2019.

Aprovado em: 20/01/2019. 